\title{
As Comunidades Virtuais
}

Rogério da Costa

\section{The Virtual Communities}


Resumo: Esse artigo trata extensivamente a respeito do florescimento das comunidades virtuais, fornecendo exemplos dessas, bem como fazendo referência aos desafios e alguns cuidados quando da construção das comunidades virtuais. Entende as comunidades virtuais como um estímulo à formação de inteligência coletiva, que nos ajuda a lidar com o excesso de informação e pode nos abrir a visões alternativas de uma cultura. Aponta para os caminhos digitais de uma nova geração, que prefere a comunicação via blogs e fotologs e o uso de uma tecnologia disponível que possibilita o encontro físico.

Palavras-chave: Comunidade virtual. Comunidade virtual móvel. Inteligência coletiva. Informação. Comunicação.

Abstract: This article deals extensively on the birth of virtual communities, offering some examples and also mentioning some challenges and things to be careful of when building a virtual community. It understands virtual communities as a stimulus to the creation of a collective intelligence, which helps us to deal with the excess of information and can open for us alternative visions of a culture. It points out to the digital pathways to a new generation, which prefers communication via blogs and photologs, and the use of an available technology that makes physical meeting possible.

Keywords: Virtual community. Mobile virtual community. Collective intelligence. Information. Communication.

COSTA, Rogério da. As Comunidades Virtuais. Informática na Educação: teoria \& prática, Porto Alegre, v.8, n. 2, p.55-73, jul./ dez. 2005. 
Quando comecei a me orientar na WELL, procurava informação e encontrei-a. Contudo, logo me dei conta de que as pessoas que dispõem da informação são mais interessantes do que a informação em si.

Howard Rheingold

\section{Colônias de formigas?}

O nome de Howard Rheingold está intimamente ligado à cultura digital. Ele foi um dos pioneiros na divulgação das comunidades on-line, tendo participado ativamente de uma das primeiras e mais famosas iniciativas de que se tem notícia na área, a WELL (Whole Earth 'Lectronic Link), fundada em 1985 pelos editores da revista Whole Earth Review ${ }^{1}$. Rheingold anima, atualmente, uma outra comunidade virtual, chamada Brainstorms. Em seu livro $A$ Comunidade Virtual, publicado em 1993, na mesma época em que a Webestava nascendo, Rheingold já desenhava um mapa detalhado dos diversos tipos de comunidades on-line existentes no mundo. Ele apontava para o importante fato de que "não existe uma subcultura on-lineúnica e monolítica, mas antes um ecossistema de sub-culturas, umas frívolas e outras sérias", e também alertava que, "seja uma comunidade aquilo que for, não se está nunca livre de conflitos".

Quase uma década depois, pode-se dizer que essas sub-culturas virtuais estão florescendo por todos os cantos do planeta. Elas são tão variadas que é simplesmente impossível mapear todas as espécies e subespécies existentes. Há comunidades virtuais reunindo interessados em esportes, entretenimento, política, comércio, saúde, sexo, jogos, raça, gêneros, e no que mais pudermos imaginar. O ritmo com que elas se formam e se desfazem acompanha, basicamente, o mesmo de todos os grupos humanos. Algumas poucas permanecem sólidas ao longo dos anos, como a WELL e, até recentemente, a The-Park, outras são promovidas pelos agentes da mídia tradicional, como a CNN e UOL, e muitas vivem da iniciativa de grupos de interesse, sejam eles empresas, ONGs, instituições educacionais, movimentos minoritários etc.

A WELL, que funciona até hoje, é o melhor exemplo de durabilidade, com seus membros cultivando relações intelectuais, afetivas e sociais. A comunidade The-Parké outro bom exemplo, tendo durado de 1994 até 2001. Com salas de bate-papo, fóruns, notícias e artigos, a The-Park teve uma população de mais de 700 mil membros, sendo que mais da metade contribuía com pequenas mensalidades. Eles podiam se tornar moderadores nos fóruns e salas de bate-papo, havendo também um banco de dados com artigos sobre os temas discutidos. Era também possível visualizar o perfil de cada participante e conhecer seu endereço eletrônico. Na primeira página do site lemos: "Nossa intenção principal é oferecer um local para que pessoas de todo o canto do mundo, que tenham algo em comum, possam se encontrar, dialogar e aprender sobre assuntos importantes, cultivar amizades, romances, relações e parcerias de negócios"2.

Dentre outros exemplos de comunidades expressivas temos a Respublica, fruto de uma iniciativa francesa de 1998, que possui cerca de 500 mil membros e contabiliza mais de 9 milhões de visitas mensais. Multimania, ligada ao site de busca Lycos, com base também na França, soma um milhão de membros. No Brasil, temos a comunidade Uol, que está estruturada unicamente em salas de bate-papo, videopapo e videochats para os visitantes. A presença simultânea de usuários já atingiu 40 mil conectados. Outra iniciativa de sucesso é Caramail, de propriedade da Lycos, baseada em chats que chegam a $20 \mathrm{mil}$ 
conectados simultâneos e mais de 40 mil fóruns de discussões, com uma população que passa da casa do milhão ${ }^{3}$.

Claro que não mencionamos aqui as mega-comunidades, constituídas pela America On Line (www.aol.com), Microsoft Network (http:/ /communities.msn.com), Geocities (www.geocities.com, ligada a Yahoo.com) e Ezboard (www.ezboard.com). O que acontece é que essas reagrupam um número enorme de micro-comunidades que vivem em seu interior, usufruindo das facilidades de suporte técnico e tecnológico oferecido.

O desenvolvimento das comunidades virtuais é provavelmente um dos maiores acontecimentos desses últimos anos, já que elas estimulam uma nova maneira de se "fazer sociedade", na expressão de Pierre Lévy, filósofo francês mais conhecido por seus livros sobre a cibercultura emergente ${ }^{4}$. Os grupos de discussão, listas de difusão, chats, mundos virtuais multiparticipantes, videogames coletivos on-line e comunidades sem fio apresentam um crescimento espetacular. As salas de bate-papo, por exemplo, são uma febre não apenas entre os jovens, mas entre pessoas de várias idades, incluindo os chats que possuem recursos 3D, com seus avatares pitorescos. O que não falta são histórias de pessoas que se conheceram em chats e fóruns e tornaram-se amigas, namoradas, casaram-se (ou se divorciaram), arranjaram trabalho, etc. Há alguns anos, aqueles que trabalham nos mais diversos tipos de negócios, nas várias esferas da administração, nas universidades e escolas têm se interconectado cada vez mais através do correio eletrônico e do site de sua instituição ou organização. Essas pessoas constituem verdadeiras comunidades virtuais de trabalho e de troca de informações e conhecimentos.

\section{Construindo sua comunidade}

O que é certo, e pouco comentado, é que o investimento pessoal e financeiro dos promotores de qualquer comunidade on-line é altíssimo. Os desafios e problemas para se construir uma comunidade virtual começam, na verdade, bem antes da questão sobre quais tecnologias utilizar e continuam bem depois que elas estão implantadas. É a relação entre membros e promotores uma das que mais oferece problemas. Nem sempre o que os membros desejam é o que os promotores estão oferecendo. Por outro lado, é muito comum promotores fazerem suposições equivocadas sobre as necessidades de uma comunidade, $e$ disponibilizarem aquilo de que ninguém precisa. Por isso é preciso um balanço constante entre as principais necessidades $\mathrm{e}$ disponibilidades de uns e de outros. Amy Jo Kim, autora do livro Community Building on the Web e uma das responsáveis pela concepção das comunidades virtuais da AOL e do iVillage, oferece três conselhos básicos nesse terreno ${ }^{5}$. Uma comunidade, em primeiro lugar, deve começar pequena e crescer lentamente como um organismo vivo, incluindo descobertas ao longo do processo, modificando-se. Os gestores, por sua vez, precisam estar atentos aos sinais que os membros emitem, procurar compreendê-los constantemente e se fazer compreender por eles. É bom ter em mente que os gestores são os responsáveis pelo comportamento ético acordado pela coletividade. Finalmente, toda comunidade deve caminhar para a autonomia de iniciativa de seus participantes, incentivando-os a expressarem suas idéias e acatando suas sugestões.

Como estratégia fundamental, Amy Kim aconselha aos promotores estabelecerem com clareza os objetivos da comunidade, bem como os benefícios que seus membros terão ao 
participarem dela. É sempre bom lembrar que a participação de alguém numa comunidade on-line implica investimento de tempo, paciência e compreensão de coisas novas, muitas vezes difíceis de serem assimiladas. A menos que o projeto consiga preencher uma necessidade real, os usuários não se sentirão motivados em participar. Sabe-se que, em geral, as pessoas vão até o lugar que lhes oferece algo de que necessitam e que não podem encontrar em outro lugar. Sendo assim, para se dedicar aos compromissos de uma comunidade virtual, é preciso que a pessoa tenha claro para si qual será seu benefício principal.

\section{As mentes coletivas}

Voltemos às análises visionárias de Rheingold em seu Comunidade Virtualde 1993. Ele percebeu que as comunidades virtuais são lugares onde as pessoas se encontram, mas são igualmente um meio para se atingir diversos fins. "As mentes coletivas populares e seu impacto no mundo material podem tornar-se uma das questões tecnológicas mais surpreendentes da próxima década", antecipava. Na verdade, a idéia de uma mente ou uma inteligência coletiva mediada por computadores não chega a ser uma novidade. Em 1976, o pesquisador americano Murray Turoff, idealizador do sistema de intercâmbio de informação eletrônica (EIES), considerado o ponto de partida das atuais comunidades online, prenunciava que "a conferência por computador pode fornecer aos grupos humanos uma forma de exercitarem a capacidade de 'inteligência coletiva' (...) um grupo bem sucedido exibirá um grau de inteligência maior em relação a qualquer um de seus membros"'.

Turoff visualizou as comunidades virtuais e o potencial de inteligência coletiva que elas envolviam, mas Rheingold percebeu nelas uma relação mais profunda, motivado em especial pela questão do excesso de informação. Com efeito, um dos problemas da rede, em sua visão, era o da "oferta demasiada de informação e poucos filtros efetivos passíveis de reterem os dados essenciais, úteis e do interesse de cada um". Rheingold estava atento ao fato de que os programadores se esforçavam para desenvolver agentes inteligentes que realizassem a busca e filtragem de informação, poupando o usuário "da terrível sensação causada pelo fato do conhecimento específico procurado estar enterrado em 50 mil páginas de informação recuperadas". "Mas já existem", dizia, "contratos sociais entre grupos humanos - imensamente mais sofisticados, embora informais - que nos permitem agir como agentes inteligentes uns para os outros".

Isso, de certa forma, ampliava o conceito de mente coletiva, pois não se tratava apenas, como imaginava Turoff, de resolver problemas em conjunto, em grupo, coletivamente, como o fazem as colônias de formigas. Ao contrário, a idéia de mente coletiva que mais seduzia Rheingold era a de um grupo estimulado a trabalhar em função de um indivíduo, dos benefícios mais claros e palpáveis que ele pudesse vir a obter. Ele nos lembra que as comunidades virtuais abrigam um grande número de profissionais que lidam diretamente com o conhecimento, o que faz delas um instrumento prático potencial. "Quando surge a necessidade de informação específica, de uma opinião especializada ou da localização de um recurso, as comunidades virtuais funcionam como uma autêntica enciclopédia viva. Elas podem auxiliar os respectivos membros a lidarem com a sobrecarga de informação". Em suma, é no horizonte do excesso de informação que encontramos as comunidades virtuais, funcionando como verdadeiros filtros humanos 
inteligentes. A estratégia de fornecimento e utilização de informação através do ciberespaço seria, na visão de Rheingold, uma maneira extraordinária de um grupo suficientemente grande e diversificado de indivíduos conseguir multiplicar o grau individual de seus conhecimentos ${ }^{7}$.

Mais recentemente, Pierre Lévy tem defendido a participação em comunidades virtuais como um estímulo à formação de inteligências coletivas, às quais os indivíduos podem recorrer para trocar informações e conhecimentos. Fundamentalmente, ele percebe o papel das comunidades como o de filtros inteligentes que nos ajudam a lidar com o excesso de informação, mas igualmente como um mecanismo que nos abre às visões alternativas de uma cultura. "Uma rede de pessoas interessadas pelos mesmos temas é não só mais eficiente do que qualquer mecanismo de busca", diz ele, "mas sobretudo do que a intermediação cultural tradicional, que sempre filtra demais, sem conhecer no detalhe as situações e necessidades de cada um"8. Lévy está profundamente convencido, da mesma forma que Rheingold, de que uma comunidade virtual, quando ela é convenientemente organizada, representa uma importante riqueza em termos de conhecimento distribuído, de capacidade de ação e de potência cooperativa.

Já Steven Johnson, que além de jornalista e escritor é um dos promotores da comunidade virtual Plastic.com (www.plastic.com), afirma num recente artigo, "The swarm next time", que os seis últimos anos da Web foram de pseudo-interatividade, e que finalmente o ciberespaço começa a nos oferecer aquilo que foi sua promessa original: alimentar uma inteligência coletiva pela conexão de todas as informações do mundo. "Podemos ver os primeiros anos da Web", diz ele, "como uma fase embrionária, evoluindo através de seus antepassados culturais: revistas, jornais, shoppings, televisões etc. Mas hoje já há algo inteiramente novo, uma espécie de segunda onda da revolução interativa que a computação desencadeou: um modelo de interatividade baseado na comunidade, na colaboração muitos-muitos"9.

Johnson não desconhece o antigo e longo percurso de comunidades como a WELL, considerada por Rheingold como um autêntico filtro comunitário inteligente. Mas o que ele tem em mente aqui são as conseqüências da intervenção cada vez mais ampla e complexa dos agentes inteligentes nas relações entre os membros de comunidades virtuais. Ele está interessado, acima de tudo, na performance dos filtros atuais, que aumenta na medida em que há um incremento do número de usuários e de informações. Isso quer dizer que os agentes e filtros colaborativos tornam-se mais espertos e úteis na medida em que mais informações e indivíduos fluem através deles.

Dois bons exemplos disso são Napster e Morpheus, softwares que permitem às pessoas trocarem músicas, imagens e arquivos entre si através da rede. Nesse caso, quanto maior o número de usuários e de documentos disponíveis no sistema, melhor é o desempenho dos softwares e, em conseqüência, maiores são os benefícios para cada um. O Napster não só funcionou, como seu sucesso resultou numa enorme batalha judicial com a poderosa indústria fonográfica. Pois bem, a contribuição de cada indivíduo no sistema Napster pode ser considerada mínima, já que eles precisam disponibilizar, quando muito, seus arquivos de música para a comunidade. São as pequenas formigas levando seu minúsculo pedaço de folha para o centro de um enorme formigueiro! Em 
contrapartida, o benefício é ter a sua disposição todas as músicas disponibilizadas por todos os membros do planeta!

É possível notar, de fato, que no mesmo ritmo em que as publicações e ofertas de produtos e serviços foram se avolumando no ciberespaço, as comunidades virtuais foram aprimorando suas técnicas de auxílio e orientação aos usuários, conquistando assim sua confiança e atraindo sua participação. Hoje, além da comunicação direta entre os membros, que funciona como fonte de dicas e sugestões, é possível contar com as mais variadas citações feitas em grupos de discussão ou em salas de bate-papo, com os votos ou críticas dos usuários a produtos e serviços, com a opinião de especialistas convidados, com serviços de personalização e, cada vez mais, com a ação dos knowbots.

Todos esses recursos fazem das comunidades virtuais verdadeiras fontes de consulta e, como conseqüência previsível, muitos visitantes usufruem mais do que contribuem. O próprio Rheingold nos dá uma estatística que é válida até hoje, a de que cerca de $16 \%$ de usuários, num fórum ou chat, contribuem com $80 \%$ do volume total de palavras, embora haja muitos à escuta, invisíveis, sendo livres de participar ou não, e que usam os recursos da coletividade como fonte variada de orientação. Ora, o fato de muitas pessoas apenas consultarem e não contribuírem diretamente com o coletivo, por si só, poderia ser entendido de forma negativa. No entanto, os agentes inteligentes vieram, em tempo, contrabalançar essa tendência, pois eles conseguem capitalizar, em prol da comunidade, até mesmo as consultas mais simples daqueles que dela não participam ativamente.

Mas que tipo de mente, afinal de contas, deveríamos atribuir às comunidades on-line? Há algumas iniciativas que alimentam conotações mais utópicas, e que levam as pessoas a duvidarem da possibilidade de uma inteligência ou mente coletiva. Trata-se daquelas que pressupõem graus elevados de sacrifício dos membros em função de algum objetivo ou causa maior. Com idéias formigando de todo lado, os indivíduos vão engendrando uma obra com a sinergia de suas inteligências ou de suas ações. Um dos raros casos conhecidos desse gênero na rede, e aliás com um sucesso extraordinário, é o da comunidade virtual OSDN.com (open source development network- www.osdn.com), que reúne programadores de todo o mundo dispostos a colaborar no desenvolvimento de softwares com código aberto. O sistema operacional Linux (que possui mais de $30 \%$ do mercado mundial de servidores - www.linux.com) é a melhor prova de resultados dessa autêntica espécie de mente coletiva. Mas a WELL também provou que uma comunidade on-line pode socorrer um membro doente num país distante, mobilizando recursos financeiros e humanos em pouquíssimo tempo ${ }^{10}$.

A segunda maneira de se interpretar uma inteligência coletiva é entender uma comunidade virtual como um excelente filtro inteligente que pode ser consultado por qualquer um a qualquer momento. Nesse caso, é o grande material acumulado no formigueiro que socorre cada pequena formiga em suas necessidades.

\section{$4 \quad$ Um zumbido na Rede...}

Vejamos um dos exemplos mais contundentes do que seria uma comunidade virtual inteiramente baseada no conhecimento, e que só pôde se constituir com a ajuda de agentes inteligentes. Trata-se de 
www.abuzz.com, criado em janeiro de 2000 pelo The New York Times. A idéia do NYT foi explorar, de uma forma inteligente, o modo como as pessoas buscam informações e conhecimentos e colaboram umas com as outras através de um ambiente on-line. Foi também, do ponto de vista comercial, uma estratégia para incorporar o potencial de participação de seus assinantes através da Internet, bem como para conseguir novos assinantes.

Uma autodefinição na primeira página diz o seguinte: "Abuzz é uma rede de conhecimentos que usa o correio eletrônico e a Web para conectar você com pessoas, informações e pontos de vista que Ihe sejam relevantes". De maneira estratégica, ele dá também uma definição de seus membros, que soa como um lembrete ético:

\begin{abstract}
"Os membros de Abuzz são pessoas inteligentes e com conhecimento como você. Eles não são experts contratados, mas pessoas que gostam de compartilhar o conhecimento pelo conhecimento. Eles são, de uma maneira distinta, o ingrediente nãotécnico que torna Abuzz mais interessante do que uma sala de bate-papo, mais conveniente do que um news group, mais receptivo do que um fórum e mais humano do que um mecanismo de busca".
\end{abstract}

Seis meses após seu lançamento, Abuzz.com tinha mais de 350 mil membros em atividade. Seu princípio de funcionamento é extremamente simples e atraente do ponto de vista do usuário, mas altamente sofisticado e complexo do ponto de vista da solução tecnológica. O principal recurso de Abuzz.com é o sistema de "perguntas e respostas", que atrai as pessoas pela simplicidade e praticidade. Simples, porque a primeira coisa que vemos na página inicial é o espaço para colocarmos nossa questão; prático, porque recebemos as respostas por e-mail. De fato, em Abuzz.com podemos perguntar qualquer coisa, desde assuntos triviais até problemas técnicos ou teóricos. Podemos nos informar sobre produtos e serviços, ou sobre os melhores sites de algum assunto. Os membros da comunidade respondem. Isso significa, obviamente, que se alguém deseja fazer uma pergunta, deve estar disposto a responder, pelo menos de vez em quando, a algumas que lhe serão formuladas. Afinal, é a reciprocidade que faz a comunidade. Mas o usuário não precisa se preocupar: o agente inteligente filtra as questões remetidas pela comunidade, e só as endereça para os membros cujo perfil combine o melhor possível com a pergunta. Dessa forma, os participantes que não tiverem se declarado amantes da música clássica, por exemplo, não serão forçados a responder questões sobre Mozart. No entanto, se por um lapso, algum desses participantes se empolgar em comentários musicais a respeito do filme Amadeus, então o agente não terá como evitar de lhe enviar algumas belas questões sobre Antonio Salieri, o famoso adversário de Mozart.

Para o agente inteligente de Abuzz.com, tudo que auxiliar na construção do perfil dos membros e na melhor troca possível entre perguntas e respostas é importante. Assim, as respostas recebem aplausos, o que estimula a participação; o tempo que alguém leva para responder é computado, para que aqueles que perguntam tenham idéia do tempo médio de resposta; caso o usuário não receba uma resposta no tempo médio, o agente lhe propõe refazer a pergunta etc. Esses e outros recursos fazem de Abuzz.com um excelente exemplo de comunidade que é movida exclusivamente pela partilha de conhecimentos, por uma inteligência coletiva.

O jornal The New York Times, por sua vez, encontrou em Abuzz.com um ambiente vivo 
que o orienta em muitas pautas e discussões. Além disso, o próprio jornal fornece links de matérias interessantes para os grupos de discussão e coloca questões sobre diversos temas para a comunidade, numa forma inusitada de provocação e diálogo. É o que poderíamos chamar de uma autêntica conversa entre um meio de comunicação impresso e seus assinantes e leitores.

\section{As redes de conhecimentos}

A televisão também tem seus exemplos interessantes na área do conhecimento. Um deles é o da emissora americana CNN e de sua comunidade on-line ${ }^{11}$. É comum, durante sua programação, a inserção de pequenas chamadas para discussões em sua página na Internet, em geral sobre os assuntos mais importantes do dia. De fato, enquanto outras emissoras são fiéis à idéia de que é preciso manter a audiência ligada o maior tempo possível em seus programas, a CNN não teme que o interesse pelos fóruns e chats que ela promove na rede possa vir a dividir a atenção dos telespectadores, numa espécie de competição entre Internet e TV. Ao contrário, a fórmula parece, no fundo, reforçar a fidelidade ao canal, já que as pessoas encontram no site o espaço adequado para prosseguir com discussões sobre assuntos de seu interesse com outros internautas. Isso faz com que a emissora atue como promotora de debates e não mais, exclusivamente, como fonte de difusão de informações. No fundo, os participantes dessa comunidade virtual possuem hoje uma visão mais ampla da própria CNN, que não se esgota na tela da televisão.

No campo do jornalismo on-line, uma boa fonte de inspiração é o site Plastic.com (www.plastic.com). Trata-se de uma comunidade virtual, composta por pessoas interessadas em usufruir de um jornalismo que é produzido, na maior parte das vezes, a partir da experiência de leitura que seus próprios membros possuem dos vários sites de notícias espalhados pela Internet. O ponto essencial é sustentar que os princípios da informação jornalística acabam por isolar os acontecimentos noticiados da esfera na qual a experiência do leitor poderia ser realmente afetada. Para tentar superar essa distância, os promotores do site propõem que seus membros escolham notícias e artigos de qualquer ponto da rede que gostariam de comentar e as enviem para a direção de Plastic.com. A coletividade, então, tem acesso a essas notícias selecionadas e podem acrescentar sua própria avaliação. Em pouco tempo um sistema de notas foi implantado para estimular os melhores comentadores. Contando com mais de 25 mil pessoas registradas, a Plastic.com teve, após um ano de lançamento, mais de 13 mil links para artigos e notícias publicados e que receberam mais de 90 mil comentários da comunidade. O site funciona como um perfeito jornal coletivo, que pode ser consultado por temas, pelas melhores avaliações, por artigos etc $^{12}$.

Uma experiência que tem se mostrado igualmente eficiente no campo do conhecimento, é o site Fathom.com (www.fathom.com), fundado no início de 2001 por um consórcio envolvendo as seguintes instituições: Columbia University, London School of Economics and Political Science, Cambridge University, The British Library, Smithsonian Institution's National Museum of Natural History, The New York Public Library, University of Chicago, Americam Film Institute, RAND e Woods Hole Oceanographic Institute. O objetivo principal de Fathom.com é atrair o 
internauta para o interior de um circuito de capital de conhecimentos e expertises autenticadas. $O$ slogan de Fathom.comé: "você deseja participar do mundo das idéias, não apenas porque elas são desafiadoras e contra-intuitivas ou complexas, mas porque você gosta disso, porque isso é bom para sua carreira, para sua alma, porque você pode". O consórcio traduz um novo conceito, o de convergência cultural, ao reunir universidades, bibliotecas, editoras e museus. Nele encontramos centenas de cursos on-line, com seus respectivos grupos de discussão, oferecidos pelas instituições, bem como inúmeros produtos relativos ao conhecimento (livros, CD-ROMs, vídeos, CDs, periódicos). Um sistema de indexação por proximidade permite ao usuário saber quais cursos oferecidos relacionam-se com quais outros, e quais produtos, referentes aos cursos, podem ser encontrados no próprio site. Isso permite uma alternância entre pesquisa em profundidade e pesquisa tangencial. Ann Kirschner, presidente de Fathom.com, diz que o site tem tido mais de 750 mil visitantes únicos por mês, e que possui mais de 100 mil usuários recebendo e-mails regularmente ao final do primeiro ano de atividade.

Já no campo da política, um site como Speakout.com (www.speakout.com) inaugura uma idéia muito recente na Internet, a da Ágora Virtual $^{13}$. Ele procura recuperar o espírito da prática política que floresceu entre os antigos gregos, que em praça pública - a ágora discutiam as questões de sua cidade. A Speakout.comé uma iniciativa que visa atrair os internautas para um cenário inteligente de discussão política. Um caso polêmico debatido recentemente no site, dizia respeito à votação de uma lei sobre ex-condenados por abuso sexual. Ela pretendia obrigá-los, quando mudassem de residência, a declararem publicamente aos vizinhos e à prefeitura local o fato de que tinham sido condenados por abuso sexual. Isso acabou gerando no site uma série impressionante de argumentos a favor e contra, que serviam muito bem para nos mostrar o quanto é complexa uma sociedade e suas idéias. Trata-se, portanto, de uma iniciativa um pouco diferente daquela de comunidades virtuais que discutem temas gerais. Na Ágora Virtual a questão é cidadania, democracia, direitos etc.

A Speakoutpossui uma audiência de 2,5 milhões de visitas mensais, sendo que 190.000 são de usuários únicos. Aestratégia é simples: como Ágora política virtual, o site consegue captar a atenção dos políticos para o que está sendo discutido. Isso dá força à palavra do internauta (netcitizen), que é assim atraído e estimulado a declarar suas idéias. Há um sistema de remessa de e-mails do usuário diretamente para os políticos ou para os partidos. São debatidas questões de sua comunidade local, de sua cidade, estado, país e do mundo. Há também o incentivo à formação de grupos de interesse, e a abertura de canais de comunicação com as autoridades competentes (é o lobby do cidadão). A transparência do relacionamento entre políticos e cidadãos no site funciona também como forma de compromisso público documentado.

Se pensarmos que as comunidades criam mundos próprios, percebemos que é essa atividade cotidiana, que inclui a publicação de textos, a indicação de links, a produção de questões e a expectativa em receber uma resposta não se sabe de quem, a ida e vinda de mensagens, enfim, é isso que cria, pouco a pouco, um mundo próprio de significação, povoado por seres virtuais: idéias, conceitos, sentidos. O objetivo maior está na sensação de pertencer a um ambiente que todos constroem 
e compartilham.

\section{Comunidades virtuais e comércio eletrônico}

Num livro extremamente provocador, chamado Cluetrain- Manifesto para uma economia digital, publicado em 1999, Levine, Locke, Searls e Weinberger, quatro autores americanos ligados ao setor de marketing, anunciam o fim dos negócios convencionais. Eles defendem a idéia de que, no fundo, negócios são conversações, e que uma poderosa rede global de troca de idéias já estaria em curso com a expansão das telecomunicações. "Através da Internet", afirmam, "pessoas estão descobrindo e inventando novas maneiras de compartilhar rapidamente conhecimento relevante. Como um resultado direto, mercados estão ficando mais espertos - e mais espertos que a maioria das empresas". Para eles, isso não seria na verdade nenhum segredo, pois parece ser evidente que o mercado em rede sabe mais que as empresas sobre seus próprios produtos. $E$ tanto sendo a notícia boa ou ruim, eles contam para todo mundo.

Mais recentemente, uma série de pesquisas confirmaram as intuições do Manifesto. Elas contrariam a idéia de que comunidade virtual e comércio não se misturam. A técnica básica utilizada pelos institutos de pesquisa, num grande levantamento feito ao longo do ano 2000 , foi a comparação entre membros ativos de uma comunidade on-line e simples visitantes dos mesmos sites. Segundo a Andersen Consulting, $62 \%$ dos compradores em Internet afirmam que as considerações de outros clientes e suas recomendações os orientaram na compra on-line. Já a Forrester Research levantou que $30 \%$ dos usuários, participantes de comunidades, afirmam que seu engajamento deveu-se ao fato de que elas o ajudam a decidir o que comprar. Constatou-se, também, que eles fazem em média 20 referências de sua comunidade virtual para outras pessoas, além de comprarem 5 vezes mais que não membros e apresentarem um período de permanência, em termos de fidelidade ao site, $50 \%$ superior aos não membros $^{14}$.

Esses dados explicam porque muitos usuários, mesmo não sendo participantes ativos de comunidades, permanecem obtendo informações através dos fóruns de discussão e dos mais variados comentários ali deixados pelos membros, pois isso os auxilia em suas compras e outras atividades. Isso indica, mais uma vez, que as comunidades vêm sendo usadas como filtros de informação.

A comunidade de comércio eletrônico mais famosa continua sendo a www.ebay.com, verdadeiro bazar composto por clientes reunidos pelo interesse comum em tópicos relacionados aos mais diversos produtos. Eles alimentam um número enorme de fóruns de discussão. Outro exemplo é o da comunidade formada pela empresa Cisco Systems, que estimula profissionais da área de infraestrutura tecnológica a compartilhar informações sobre produtos e tecnologias em seus fóruns (http:// forums.cisco.com). A comunidade patrocinada pela AT\&TWorldNet(http://communityport.att.net/ ) possui inúmeras salas de bate-papo, fóruns extremamente variados, concursos e eventos. No Brasil, a Sabido.come Icomo.comsão bons exemplos de espaços de discussão e informação sobre produtos e serviços. Há também comunidades de vendedores e compradores em sites de comércio eletrônico, trocando informações relacionadas a preço, qualidade, estoques etc. A Amazon.comé, de 
certa forma, um bom exemplo desse tipo de comunidade.

Todas essas iniciativas têm objetivos muito claros: fidelização dos clientes, incremento de negócios e vendas, redução de custos na captação de membros, melhor compreensão de seu mercado através da contínua conversação entre os usuários de sua comunidade, etc.

\section{O enxame dos "sem fio"}

A enorme evolução das comunidades virtuais está profundamente ligada ao esforço despendido pelas pessoas durante a década de 90. Elas estabeleceram laços sociais, comerciais e amorosos através de seus desktops. Elas aprenderam a conversar nas salas de bate-papo, a discutir sobre os mais variados assuntos nos fóruns, a enviar e receber e-mail para resolver todo tipo de problema, a participar de listas de discussão e de grupos de notícias. Em suma, a Internet lhes possibilitou a invenção de novas formas de comunicação, sem grandes preocupações com a presença física ou com a situação geográfica dos interlocutores, sem precisar sequer dar importância, muitas vezes, ao gênero ou situação social daqueles com quem se conversava.

Contudo, parece que o início do século 21 está preparando outra mutação na maneira como as pessoas se comunicam. Se olharmos para a direção certa, será possível detectar os primeiros sinais de comunidades virtuais distanciando-se dos desktops e saindo do ciberespaço. É a chegada das comunidades "sem fio". A essência desses novos grupos tem um nome: mobilidade. Eles se conectam por telefones celulares, palmtops ou pequenos rádio transmissores de curto alcance. São os portáteis. O essencial é poder estar "sempre ligado" em qualquer lugar ${ }^{15}$.

A revolução real na computação sem fio não é comercial ou tecnológica, mas social. Conectadas a todo momento e em qualquer lugar, as pessoas podem comunicar e cooperar de novas maneiras. Na Finlândia e no Japão, países que oferecem com sucesso essa tecnologia há mais tempo, os serviços de dados para dispositivos móveis tornaram-se uma plataforma importante para a interação de grupos. Isso acabou surpreendendo os que só acreditavam nesses novos serviços como outra maneira de se acessar conteúdos.

As dificuldades em se navegar nos sites especialmente criados para quem possui um celular ou palmtop (os assim chamados serviços WAP), aumentaram a importância das mensagens de textos simples para a interação entre os mais diversos grupos. Na Europa, e principalmente na Finlândia e Suécia, o que tem feito muito sucesso entre os usuários de portáteis é o serviço SMS (Short Messaging Service - serviço de mensagens curtas), que é o equivalente no mundo dos "sem fio" ao e-mail dos computadores. Hoje ele é o serviço mais comum na Europa, sendo que ao longo de 2001 foram mais de 200 bilhões (isso mesmo!) de mensagens enviadas. Além do SMS, os conhecidos serviços de e-mail, comunicador instantâneo e chat também estão disponíveis nos aparelhos móveis. No Brasil, o SMS também já é oferecido como serviço por muitas operadoras de telefonia celular, mas ele é bem menos conhecido do público - tanto quanto ele é pouco divulgado.

Mas o que são essas comunidades virtuais móveis? Como será que elas funcionam em aparelhos como os celulares e palms, por exemplo? Eles são tão minúsculos e 
desajeitados para falarmos ou tomarmos nota de algo, que fica impossível imaginar que alguém consiga, além disso, digitar mensagens para participar de um chat! Será que nossas definições de comunidade ainda se aplicam nesse caso?

As pessoas associam comunidade virtual, em geral, com as mensagens lineares que podem ser acompanhadas num fórum de discussão on-line. Mas o modo como essa discussão é experimentada na tela do computador, não é o mesmo de como ela o é num celular, palm ou pager. As restrições do tamanho da tela, da memória, da banda de transmissão e da navegação acabam quebrando o curso linear de uma conversa em inumeráveis pedaços. Os usuários, então, só têm acesso a partes da discussão, o restante estando acessível apenas em seus PCs. No caso dos chats, inventou-se um sistema bem original para facilitar a composição de mensagens no telefone celular: as shortcuts, um pequeno arquivo com mensagens préprogramadas. Digitando-se dois ou três caracteres, podem-se obter rapidamente expressões, frases, perguntas e respostas prontas, que ajudam o usuário nessa árdua tarefa que é escrever dispondo de oito teclas ${ }^{16}$.

Os agentes inteligentes também desempenham um papel importante nos aparelhos móveis, justamente porque tarefas como digitar mensagens e navegar através de menus ainda são particularmente difíceis nesses dispositivos. O uso de agentes serve para atenuar o esforço da pessoa, seja antecipando a palavra que ela começou a digitar, seja reduzindo uma lista de restaurantes locais com base em suas preferências ou the auxiliando na busca de informações relevantes ${ }^{17}$.
Ora, mesmo com esses recursos disponíveis, que permitem quando muito uma comunicação monossilábica, fica difícil pensar numa comunidade virtual móvel de forma similar aos grupos que se formam na Internet. Essa última parece ser um ambiente mais favorável à multiplicação de idéias, de comentários e discussões, assim como é propícia à busca por informações complexas. Sob esse aspecto, o ciberespaço é mesmo um lugar desprovido de materialidade, de presença física, que é aliás aquilo de que muitos reclamam. O ciberespaço é basicamente um meio que favorece a comunicação não presencial.

Já as comunidades virtuais que se formam em torno de celulares, palmtops e outros dispositivos sem fio têm funcionado, cada vez mais, como apoio a ações coordenadas de grupos num espaço geográfico. Por isso a afirmação de que a essência dessas comunidades é o movimento, a reunião dos grupos em espaços físicos. É conhecido o exemplo em que grupos de jovens adolescentes de Helsinque, conectados em seus celulares por todo o canto, combinam numa fração de segundos um encontro num shopping. Eles chegam como enxames!

Essas comunidades servem, literalmente, para muitas pessoas se acharem umas às outras, e se conhecerem em grupo. Isso é experimentado em raras ocasiões quando se trata de comunidades que evoluem na Internet. Mas aqui, entre os sem fio, encontrar-se presencialmente parece ser o que há de mais interessante. Rheingold nos fala de ativistas que se mobilizam nas ruas e de jovens que se encontram em clubes. É o oposto dos filmes de ficção científica, em que chips são inoculados em seres humanos para controlálos em suas ações e deslocamentos físicos. 
Aqui, parece que um potencial de revolução permanente encontra-se entre as mãos dos jovens.

Dois produtos para crianças e adolescentes, lançados recentemente nos Estados Unidos, chamam a atenção justamente para esse fato. Um deles é um curioso brinquedo lançado pela empresa Hasbro, que é alimentado com três pilhas e opera através de uma banda de rádio de curta distância. As crianças compõem mensagens com uma caneta, seja tocando-a no minúsculo teclado ou escrevendo diretamente na tela, como num palmtop. Depois, basta aos membros de um suposto "grupo secreto" ou de uma "Sociedade dos Cavaleiros de Avalon" pressionarem um botão e pronto: mensagens são enviadas de uns para os outros através de ondas de rádio que alcançam a vizinhança. $E$ isso sem que seus pais tenham que pagar qualquer tarifa ao final do mês ${ }^{18}$

Outra novidade é a que a empresa Cybiko está promovendo, um aparelho bem esperto que oferece comunicador instantâneo e jogos interativos para crianças e adolescentes. É preciso estar a uma certa distância de outro usuário para poder receber os avisos e jogar. $\mathrm{O}$ aparelho vibra quando um amigo - ou alguém que satisfaz uma especificação qualquer - entra em seu raio de ação num shopping, num cinema ou em qualquer lugar em que a criança esteja ${ }^{19}$.

Esses dois exemplos servem para indicar o quanto as novas gerações estarão sendo formadas numa cultura em que a dinâmica parece ser a da mobilização física promovida por um espaço virtual, ao qual se está permanentemente ligado, não importa aonde se esteja. Rheingold acredita que já nasceram as crianças que jamais usarão um $\mathrm{PC}$.

\section{Blogs e fotologs - A nova "cultura"}

Os blogs parecem uma espécie de reação à afirmação de que na Web haveria uma proliferação de identidades simuladas. No caso dos chats, isso parecia bem evidente para alguns críticos, devido em grande parte à enorme quantidade de nicknames. Em fóruns isso seria menos evidente, mas não menos temerário, já que supomos estar em um ambiente "mais sério". O fato é que a identidade no mundo on line sempre provocou polêmicas. Basta ver as discussões conduzidas pelos teóricos da Ead e seu pavor de que o aluno "do outro lado do computador" não seja realmente ele! Ou então todos os problemas provocados por maníacos sexuais que assediam jovens através de salas de bate-papo. Contudo, há teóricos que afirmam que a maioria dos usuários da Internet provavelmente não constrói deliberadamente novas identidades (HINE, 2000). Devido então à proliferação dos chats e dos avatares e nicknames, construiu-se um pouco essa imagem de que na Webas pessoas não são as pessoas, ou de que há um enorme jogo de faz de conta funcionando por detrás de milhares de mentes "verdadeiras".

A chegada dos blogs causa surpresa nesse aspecto. Essa nova forma de publicação on line propõe de cara ser uma legítima e autêntica representação de seu autor. Manifestação pura de sua intimidade. O que não era possível na correria dos chats e na confusão dos fóruns (porque fórum sempre foi uma luta para desatar as muitas linhas discursivas, ou uma autêntica polifonia), agora é possível com os blogs, onde alguém pode se construir diariamente, cumulativamente, e conversar a partir de um certo ponto de vista, de sua zona iluminada! Aqui podemos nos lembrar das teses de Leibniz e dos muitos caminhos possíveis 
que podem ser percorridos dentro de uma mesma cidade. São diferentes os percursos para cada indivíduo, diferentes portanto a forma como cada um pode perceber onde vive, vivendose no entanto na mesma cidade. Se somarmos todos os percursos, teremos reconstituído uma pluralidade de mundos dentro de um mesmo e único mundo!

Do mesmo modo, para além do seu próprio blog, para além dessa pequena região iluminada de cada um, há os links, que promovem justamente a existência de um mundo maior que o mundo pessoal. Pertencer a um mundo, eis o que o blogueiro também quer. $\mathrm{E}$ a remissão de links pode ir ao infinito pois, diferentemente da grande maioria dos sites, a liberdade de se colocar links em blogsé também o que dá a sua força e interesse. Nesse jogo de referências, vale lembrar dos softwares gratuitos de referrers, ou seja, dos softwares que revelam os sites ou blogs que fazem referência ao seu, aqueles que possuem um link para você. No caso dos blogs, o fato de haver uma comunidade de "blogueiros" já nos dá uma idéia, mesmo que aproximada, de quem refere-se a quem. Isso produz uma visão de mundoWeb mais palpável do que nas comunidades virtuais via chate fórum. Os blogs são povoados por outdoors, verdadeiras portas que nos levam aos mundos vizinhos do blogueiro, zonas de proximidade semântica. $A$ referência aqui é proposital, pois se trata mesmo de uma espécie de web semântica (aquela proposta por Tim Berners-Lee), só que construída no braço pela rede de "blogueiros".

\section{A identidade $X$ perfil dinâmico}

Como diz Christine Hine, "ao invés de se perguntar sobre o que são identidades realmente e se a realidade está realmente lá, melhor é procurar saber como, onde e quando identidades e realidades são tornadas disponíveis na Web".

Há que se notar, com relação ao problema da identidade, que a experiência on line pôs à prova esse velho tema filosófico. Isso ficou muito claro quando tivemos a explosão de agentes inteligentes que funcionavam com base na auto declaração do perfil das pessoas. $O$ melhor exemplo é o que funciona no site do New York Times, abuzz.com, que nos mostra o quanto é difícil para uma pessoa o ato de se auto declarar, ou seja declarar suas preferências, seus conhecimentos, suas competências. Todos nós, quando confrontados com a necessidade da auto-avaliação ou auto descrição, somos menos fiéis do que gostaríamos de ser. Não por vontade de enganar aos outros ou a nós próprios, mas sobretudo porque esse tipo de inflexão sobre si não é usual. Não é que não pensemos em nós, mas não nos confrontamos cotidianamente com a necessidade de se descrever! Portanto, de se colocar para fora de si, de se apresentar.

A experiência do Abuzz mostra que, de fato, é na dinâmica das ações que melhor compreendemos uma pessoa, seus gostos, preferências, conhecimentos, etc. Não esqueçamos que todo coletivo é uma negociação constante de preferências. O que o agente inteligente do Abuzz faz é construir um perfil dinâmico da pessoa, seguindo seus passos no site, procurando "entender" o que ela efetivamente gosta ou prefere. Esse perfil dinâmico acaba por se diferenciar em muito daquilo que foi declarado inicialmente pelo usuário como sendo "minhas preferências". Então, no caso da comunidade virtual Abuzz, as pessoas passam a interagir segundo suas mais legítimas preferências e acabam por receber de uma máquina, como feedback, uma imagem de si, que talvez possa até lhe 
surpreender, mas que é baseada no que de fato ela faz, troca, pratica, conversa, etc. O agente inteligente não investiga quem as pessoas "realmente" são, ele apenas procura interagir com características de sua identidade com as quais entra em contato. Assim, as identidades são tratadas como performances localizadas, como perfis dinâmicos.

\section{A fabulação: construção coletiva da intimidade e do imaginário}

No caso dos blogs as coisas são ainda diferentes em relação às conhecidas comunidades virtuais. De fato, dizer que um blog pessoal é uma espécie de diário íntimo seria não atentar para o que de fato ocorre. A pessoa até pode começar seu blog valendo-se de suas lembranças cotidianas, que incluem notícias, assuntos corriqueiros, ouvi dizer, além dos aspectos pessoais, aquilo que mais propriamente pertenceria ao "íntimo". Mas a simples publicação dessas lembranças, contudo, faz delas outra coisa, algo que pode ser interpretado por um outro, avaliado e comentado. A partir do momento em que uma interpretação (sob o nome de comentário) se interpõe nas "páginas" do blog, o que de fato começa a dirigir a composição do blog é uma mistura de pessoas, de pontos de vista, de interesses e preferências. Voltamos ao aspecto do jogo de preferências como química dos coletivos. Desde que alguém se põe a falar sobre "si", este "si" adquire diversas faces dependendo das interpretações com as quais ele se defronta. Os caminhos do "si", seus desdobramentos página após página não são, digamos assim, definidos por ele próprio, mas pela rede que passa a formar, e da qual depende de certa forma. O que presenciamos, então, é uma espécie de construção coletiva da intimidade.
O blog não seria então exatamente um diário, forma que guarda sobretudo opiniões não publicáveis sobre os que rodeiam alguém. Isso porque essas opiniões são muitas vezes "disruptivas", desagregadoras, nocivas em relação ao outro, e outras vezes não publicáveis porque retratam pontos frágeis do próprio autor, situações de temor não resolvido, fruto exclusivo da relação entre a "cabeça" de quem as produz com o mundo (real ou imaginário).

Talvez por isso muitos blogs possam ser considerados uma manifestação do narcisismo ainda mais forte do que os diários. Em sua confecção eles procurariam preservar seus autores da exposição de "segredos" que seriam lançados no mundo aberto dos comentários. Por outro lado, é aqui justamente que reside a força maior dos blogs: afinal quem se interessa por esses pequenos segredos, por esse cotidiano tão cotidiano que se torna intolerável, insuportável, como diz Deleuze! Diante do intolerável e do insuportável só nos resta fabular! É aqui que começa a literatura, o momento em que alguém se põe a fabular sobre si e sobre o mundo.

\section{Literatura blog}

Essa discussão a propósito da fabulação nos leva por caminhos bem interessantes. Muitos percebem hoje nos blogs uma nova forma de literatura. Há realmente escritores que se utilizam de blogs para construir seus textos, outros para conversar com o público, ter idéias, como se diz. O fato é que há 10 anos atrás diziam que a literatura estava moribunda, quase defunta. Diante de uma máquina editorial e de distribuição inteiramente dirigida pelo mercado, pelo hit-parade, pelos top ten, como dizia Deleuze, pela política dos best sellers, não restava mesmo muito coisa aos jovens perdidos no deserto da literatura 
senão mendigar de porta em porta, como aliás o fizeram muitos nomes da literatura mundial, Henry Miller que o diga.

Acontece que a cosmo demoníaca hoje virou outra coisa, virou uma inflação de escritura, palavras e frases publicadas por todos os lados. Os jovens escritores não estão mais no deserto, estão no meio de uma avalanche de blogs, que é a forma moderna de produção através da qual eles têm que se afirmar, realizar uma obra. Hoje esse jovem não está mais no limbo, solitário, no abandono do único mundo sobre o qual, finalmente, ele deveria escrever. Agora esse jovem autor se debate em meio a uma profusão de interpretações do mundo, que soam como um alvoroço em meio ao qual ele deve lançar suas frases, verdadeira construção coletiva de nosso imaginário contemporâneo.

A fabulação, não esqueçamos, é a construção de muitos mundos nesse único mundo, é a produção de uma dimensão afetiva e artística que salta do interior mesmo da banalidade cotidiana. É por exemplo o poder dos documentários de Jean Rouch e Eduardo Coutinho. O homem comum não fala apenas de sua miséria, da falta, da injustiça que lhe acomete. Ele tampouco fala apenas do blá blá blá cotidiano que nos rodeia, esse universo do efêmero que alimenta nossas redes sociais. $O$ homem comum também fabula, também produz beleza através das palavras (lembram-se do Brasil Legalde Regina Casé. Os blogstraduzem melhor que os chats essa banalidade cotidiana, que preenche a vida de todos nós. Mas também nos abrem para os efeitos de fabulação, como em Clara Averbuck e Joca Reiners Terron.

\section{Fotologs}

Os fotologs são, em sua maioria, trabalhos em fotografia mais do que fotos pessoais. Essas, na verdade, freqüentam muito mais os blogs do que os flogs. Um flog é uma interpretação do mundo através da câmera fotográfica de seu autor ou de fotos que ele considera especiais. Com certeza os fotologs são ótimos suportes para experimentações em arte e, mais ainda, para uma arte com interação através dos comentários que as pessoas deixam. Além disso, é possível navegar horas por flogs através dos links na lista dos fotologs dos amigos. Como a lista é composta por pequenas fotos, podemos navegar de link em link só pelo prazer que as fotos nos despertam. Então, há uma relação entre os flogs e a construção de uma comunidade orientada pelo olhar, pela fruição das imagens. É uma forma de compartilhar coletivamente tanto seu ponto de vista sobre o mundo, como incluir nele sua estética. Um flog desse gênero bem conhecido é o da brasileira Sinistra (www.fotolog.net/ sinistra). Trata-se de uma fotonovela construída

\section{Referências}

BRADSHAW, Jeffrey M. (org.). Software Agents. Massachusetts: MIT Press, 1997.

D’AMARAL, Márcio Tavares (org.). Contemporaneidade e Novas Tecnologias. Rio de Janeiro: Sette Letras, 1996.

DAVENPORT, Thomas; BECK, John. A economia da atenção. São Paulo: Campus, 2001

DIZARD JÚNIOR, Wilson. A Nova Mídia. Rio de Janeiro: Jorge Zahar, 2001.

ERCÍLIA, Maria. Internet. São Paulo: FolhaExplica, 2000.

FIGALLO, Cliff. Hosting Web Communities: building relationships, increasing customer loyalty, and maintaining a competitive edge. Nova lorque: Wiley Computer Publishing, 1998 
FOSTER, Don. Author Unknown: on the trail of anonymous. Nova lorque: Henry Holt \& Company, 2000.

FRAGOSO, Suely. De Interações e Interatividade. In: Compós, X Encontro. Santos: Universitária Leopoldianum, 2001.

HAYLES, Katherine. How we became post-human: virtual bodies in cibernetics, literature and informatics. Chicago: Chicago Press, 1998.

HINE, Christine. Virtual Ethnography. Londres: Sage Publications, 2000.

JENSEN, Jens F. "Interactivity - Tracking a New Concept in Media and Communication Studies". In: Paul A. Mayer (org.), Computer Media and Communication. Oxford: Oxford University Press, 1999.

JOHNSON, Steven.Cultura da Interface. Rio de Janeiro: Jorge Zahar, 2001.

KIM, Amy Jo. Community Building on the Web. Berkeley: Peachpit Press, 2000.

LEMOS, Andre; PALACIOS, Marcos (org.). Janelas da Cibercultura. Porto Alegre: Sulina, 2001.

LÉVY, Pierre. A Conexão Planetária: o mercado, o ciberespaço, a consciência. São Paulo: Editora 34, 2001.

Cibercultura. São Paulo: Editora 34, 1999.

MAES, Pattie. Agents That Reduce Work and Information Overload. In: Jeffrey M. Bradshaw (org.), Software Agents. Massachusetts: MIT Press, 1997.

ROBINS, Kevin; WEBSTER, Frank. Times of the Technoculture: from the information society to the virtual life. Nova lorque: Routledge, 1999.

SHAPIRO, Andrew. The Control Revolution. Nova lorque: Public Affairs, 1999.

STEFIK, Mark. Focusing the Light: Making Sense in the Information Explosion. In: The Internet Edge. Massachusetts: MIT Press, 1999.

STEFIK, Mark. Internet Dreams: archetypes, myths, and metaphors. Cambridge, Massachusetts: MIT Press, 1996.

SWANN, Phillip. TV dot Com: the future of interactive television. New York: TV Books,2000.

TURKLE, Sherry. Life on the screen. Nova lorque: Simon \& Schuster, 1995.

VAZ, Paulo. "Mediação e Tecnologia". In: Mídia, Cultura e Tecnologia. Rio de Janeiro: Revista Famecos, dezembro de 2001, pgs 45-58.

WERTHEIM, Margaret. Uma História do Espaço de Dante à Internet. Rio de Janeiro: Jorge Zahar, 2001.

\section{Notas}

1 Vide <http://www.wholeearthmag.com>, <http://www.well.com>, <http://www.rheingold.com>.

${ }^{2}$ Apesar de encerrada, a página continua ativa: ver acima: <www.the-park.com>.

${ }^{3}$ Vide idem: <www.respublica.fr>, <www.multimania.fr>, <www.caramail.com>.

${ }^{4}$ Pierre Lévy, Cyberdémocratie. Paris: Odile Jacob, 2002.

${ }^{5}$ Amy Jo Kim, Community Building on the Web. Berkeley: Peachpit Press, 2000. Pode-se consultar o site da autora, www.naima.com/community, que possui links para sites que disponibilizam ferramentas para se construir comunidades virtuais, fóruns de discussão sobre o assunto, etc. Outro livro importante é o de Cliff Figallo, antigo diretor da comunidade WELL, Hosting Web 
Communities: building relationships, increasing customer loyalty, and maintaining a competitive edge. New York: Wiley Computer Publishing, 1998.

${ }^{6}$ Turoff, 1976, citado por Rheingold, A Comunidade Virtual. Lisboa: Gradiva, 1996.

7 Rheingold atesta, contra os incrédulos que desconfiam desse tipo de troca de conhecimentos e informações, que "na comunidade virtual que melhor conheço, o conhecimento bem apresentado é uma valiosa moeda de troca (...) Quem fornece respostas rigorosas e bem escritas ganha prestígio ante toda a audiência virtual. Os especialistas entram em competição para a resolução dos problemas".

${ }^{8}$ P. Lévy, op. cit.

${ }^{9} \mathrm{O}$ artigo em questão, publicado na Web em 15/01/01, pode ser encontrado procurando-se por "feedmag" em <www.archive.org>

${ }^{10}$ Cf. Rheingold, op. cit., cap. 1.

$11<$ <ww.cnn.com>

12 Seguindo um pouco esse gênero, encontramos em www.salon.com uma comunidade que funciona com comentários sobre os mais diversos assuntos, notícias, produtos e serviços. No Brasil, um exemplo é o do site Caros Amigos, que possui uma comunidade virtual bem ativa e que se formou em torno das notícias e informações veiculadas pela revista.

${ }_{13}$ Ver também <www.politics.com> e <www.grassroots.com>

${ }^{14}$ Essas pesquisas encontram-se disponíveis em <www.participate.com/research/>

${ }^{15}$ Os americanos utilizam as expressões: wireless, para sem fio, always on, para sempre ligado.

${ }^{16}$ Exemplo de alguns shortcuts disponíveis em <www.mgage.com>: digita-se "@1" para se obter "Hi There!", “@2" para "Nice to meet you all", “@30" para "Wanna go to the movies?", e assim por diante.

${ }^{17} \mathrm{O}$ agente que antecipa as palavras que o usuário está digitando no celular é fruto da tecnologia T9, desenvolvida pela empresa

Tegic, subsidiária da AOLTime Warner. Essa tecnologia já está disponível em alguns aparelhos no Brasil.

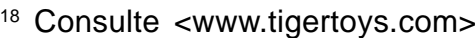

${ }^{19}$ Consulte $<w w w . c y b i k o . c o m>$

Recebido em novembro de 2005

Aceito para publicação em dezembro de 2005

\section{Rogério da Costa}

Professor no Programa de Pós-graduação em Comunicação e Semiótica da PUC-SP.

E-mail: rogcosta@pucsp.br 
INFORMÁTICA NA EDUCAÇÃO:

teoria \& prática 